\title{
EXPLORATION OF SEISMIC PERFORMANCE OF SQUARE STEEL TUBE RECYCLED CONCRETE COLUMN - RECYCLED CONCRETE DEEP FLEXURAL BEAM COMBINATION FRAME STRUCTURE
}

\author{
Xiaohong Shi \\ Sichuan College of Architectural Technology, Sichuan 618000, China \\ Email: shixiaohong7809@126.com
}

\begin{abstract}
To enhance the seismic performance of the recycled concrete deep flexural beam combination frame structure and increase the utilization rate of the square steel tube recycled concrete structure, on the basis of the previous research, starting from the structural level, the related seismic performance of the square steel tube recycled concrete column - recycled concrete deep flexural beam combination frame structure was studied in depth, so as to provide references for further theoretical research and application of square steel tube recycled concrete frame structure. Six sets of frames were designed and made for repeated low-cycle loading test, the failure process and failure form of the frame and the filled wall were observed, and the hysteretic curve, skeleton curve and strain changes at key parts of the specimens were obtained. In addition, the seismic performance of the specimen was analyzed in detail to study the influence of various parameters on the seismic performance of the structure. The results showed that the calculated values were in good agreement with the measured values, which can provide reference for the theoretical calculation of the structure. It was of great significance to conduct in-depth research on the new-type combination frame structure of square steel tube recycled concrete column - recycled concrete deep flexural beam, reveal its failure mechanism and seismic performance, and put forward reasonable structural measures, and this was an essential step for the promotion and application of square steel tube recycled concrete structure.
\end{abstract}

Keywords: Square Steel Tube Recycled Concrete Column; Recycled Concrete Deep Flexural Beam, Seismic Performance Test; Research Theoretical Analysis.

\section{Introduction}

In recent years, earthquakes in China have occurred frequently. The earthquakes in Wenchuan, Yushu and Ya'an all caused a large number of casualties and serious property losses. The earthquake damage once again demonstrated the importance of the seismic performance of the building structure. At present, with the rapid development of China's economy, a large amount of construction waste is generated in road renewal, urban renewal, new buildings and other engineering projects. At the same time, after each major disaster (such as earthquake), a large number of houses will collapse, which will also produce a huge amount of solid waste [1].

According to statistics, in China, cities can produce about 6 billion tons of all kinds of waste every year, and construction waste accounts for $40 \%$ of the total, about 2.4 billion tons [2]. For these construction wastes, most of them are transported to the surrounding areas for simple landfill treatment or directly placed in the open air without any treatment, which wastes a lot of land and resources and brings a lot of inconvenience to the daily life of local residents; in addition, a large amount of landfill and construction waste will undoubtedly bring harm to the surrounding environment, affecting air quality and polluting local waters. In some cities with fragile natural environment, land shortage and high living standards, the social and environmental problems caused by construction waste are particularly prominent. In addition, with the booming development of the construction industry, the demand for sand aggregate is also increasing. Because of its low price and wide sources, sand aggregate is often regarded as inexhaustible and inexhaustible, it is often developed at will [3].

According to statistics, more than 4 billion cubic meters of concrete and more than 608 billion tons of gravel aggregate are used worldwide every year [4]. Such a huge demand for gravel aggregate will certainly lead to a large number of rock excavation, thus damaging the original hydrogeological environment [5]. In addition, the formation of natural gravel requires a long geological time, if 
unrestrained exploitation is carried out now, then in the near future, people will inevitably face the problem of natural aggregate shortage, just like oil shortage, coal shortage and other problems today. How to solve the above problems has become a hot issue in the field of concrete research at home and abroad in recent years [6].

Recycled aggregate concrete (RAC) technology is one of effective methods to solve these problems. RAC refers to the new type of concrete made by recycling the waste concrete blocks and forming new aggregate after crushing, cleaning and screening, and partially or completely replacing the natural aggregate. It not only solves the problems of environmental pollution caused by construction waste and stacking and occupying land, but also protects the ecological environment of the origin area of concrete aggregate [7]. As a kind of green concrete with sustainable development, it has obvious environmental benefits, social benefits and economic benefits, so its application prospect is very broad [8]. The surface of recycled aggregate is coated with partially hardened cement mortar, and it will produce more or less original damage during its use, thus resulting in a large number of micro-cracks inside the aggregate. Therefore, the relevant mechanical properties of cycled aggregate are bound to be different from that of ordinary concrete [9]. A large number of domestic and foreign research literatures have reported it. The research shows that the strength, deformation performance, elastic modulus, safety and reliability of RAC prepared from recycled aggregate are worse than that of the ordinary concrete prepared from natural aggregate [10]. These defects seriously affect the further promotion, application and development of RAC. How to solve or make up for the above defects and apply RAC to buildings with high technical requirements in the new era is a key issue [11]. When the concrete is pressed in three directions, its compressive strength and deformation capacity will be greatly improved. Therefore, the RAC can be filled to steel pipe to form a new type of bearing structural system, that is, recycled aggregate concrete filled steel tube structure (RACFST) [12]. The restraint effect of steel pipe on core RAC is used to make up its initial defect and make it in a three-directional pressure state, so as to improve its deformation performance and compressive strength [13]. At the same time, the existence of core RAC can delay the local buckling of the steel pipe, thus strengthening the stability of the steel pipe. In addition, the steel tube can also be used as the template for pouring its core RAC, which can speed up the construction progress and save a lot of formwork cost [14].

At present, the research on the concrete filled steel tube structure (CFST) has been matured at home and abroad. Compared with the common CFST structure, the filling materials inside the steel tube are different in physical and mechanical properties, which will inevitably lead to the difference in mechanical properties between RACFST structure and CFST structure [15]. Therefore, the design methods and construction measures adopted by the two are also different, and it is necessary to study the performance of RACFST structure. At present, many scholars at home and abroad have studied RACFST structure, but most of the research focus on the component level. The mechanical performance of recycled concrete filled steel tube column is similar to that of ordinary concrete filled steel tube column. Therefore, it can be concluded that recycled concrete filled steel tube structure is one of the effective ways to recycle waste concrete. However, the research on the overall performance of RACFST column in frame structure, especially its seismic performance, is still blank. The RACFST frame has good seismic performance. In addition, the square steel tube concrete structure is favored by more and more engineers because of its beautiful appearance, simple beam-column joint form, easy handling during construction, and low cost.

In modern architecture, with the increase of architectural functional requirements or irregular plane shape, short span frame beam is often formed in some parts. Generally, its calculated span height ratio is between $3-6$, which belongs to the category of deep flexural beam (short beam). For example, the transfer beam in the transfer floor of a high-rise building, a large number of frame short beams formed when columns are arranged on both sides of the longitudinal inner corridor, and some important building parts, such as fire escape passageway, which play an important role in structural safety. Brittle shear failure often occurs in the deep flexural beam parts of the structure under the action of earthquake. Once damage occurs in these parts, irreparable loss of personnel and property is very likely to occur.

The main innovation point of this study is to study the seismic performance of steel tube recycled concrete column- recycled concrete deep flexural beam combination frame from the structure level, reveal its failure characteristics and mechanism under the earthquake, and analyse its relative seismic performance indexes.

\section{Seismic Performance Test of Square Steel Tube Recycled Concrete Frame}

\subsection{Experiment design}

Six specimens were designed and tested, taking into account two running parameters, that is, the recycled coarse aggregate replacement rate $\gamma$ and the axial pressure ratio $n$. The specific design parameters of the specimen were shown in table 1. 
Among them, the single parameter change specimens of replacement rate were S-1, S-2, S-3 and $\mathrm{S}-4$, respectively, and the corresponding replacement rates were $0 \%, 30 \%, 70 \%$ and $100 \%$, respectively; and single parameter change specimens of axial pressure ratio were S-4, S-5 and S-6, respectively, and the corresponding axial pressure ratios were $0.8,0.7$ and 0.6 , respectively. Wherein, the axial force $\mathrm{N}$ applied to each test piece during the test was kept constant, and the coarse aggregate replacement rate of the RAC was changed, so as to change the RAC axial compressive strength $f_{c}$; steel ratio $\alpha=A_{s} / A_{c}, A_{s}$ is the section area of the external steel pipe, $A_{c}$ is the section area of core RAC; confinement coefficient $\theta=A_{s} f_{y} / A_{c} f_{c}, f_{y}$ is the actual measured yield strength of steel pipe; slenderness ratio $\lambda=2 \sqrt{3} L_{0} / B, \quad L_{0} \quad$ is the calculated height. The loading end of the upper reinforced concrete was clamped by two steel plates with large rigidity, so as to realize the transfer of horizontal load. The loading end was approximately rigid body, in the process of repeated loading, the bending deformation at the loading end can be ignored, so the calculated height was set as L (850 $\mathrm{mm}$ ), B was the outer length of the square steel pipe, which was set as $150.9 \mathrm{~mm}$, and the measured thickness of the square steel pipe was $5.0 \mathrm{~mm}$. The geometric size and structure of the specimen were shown in figure 1 . The geometric size and structure of all the specimens were consistent, and yellow paint was sprayed on the surface of the steel tube to facilitate the marking and positioning on the surface of the steel tube, observe the peeling of the paint when the steel tube began to bulge, and easily find the bulge part.

Table 1. Design parameters of the specimen

\begin{tabular}{|l|l|l|l|l|l|l|}
\hline Number & $\lambda$ & $\mathrm{n}$ & $\alpha$ & $\theta$ & $\mathrm{L}$ & $\mathrm{B}$ \\
\hline $\mathrm{S}-1$ & 0 & 0.8 & 0.15 & 1.6 & 850 & 150 \\
\hline $\mathrm{S}-2$ & 30 & 0.8 & 0.15 & 1.6 & 850 & 150 \\
\hline $\mathrm{S}-3$ & 70 & 0.8 & 0.15 & 1.5 & 850 & 150 \\
\hline S-4 & 100 & 0.8 & 0.15 & 1.6 & 850 & 150 \\
\hline S-5 & 100 & 0.7 & 0.15 & 1.6 & 850 & 150 \\
\hline S-6 & 100 & 0.6 & 0.15 & 1.6 & 850 & 150 \\
\hline
\end{tabular}

The test adopted Q235 straight welded square steel pipe, 42.5R grade cement, ordinary natural river sand, urban tap water, natural coarse aggregate and recycled coarse aggregate. Recycled coarse aggregate and natural coarse aggregate were screened in the same sieve with a maximum particle size of $20 \mathrm{~mm}$, both of which were continuously graded crushed stone. The replacement rate $\gamma$ of recycled coarse aggregate was based on $0 \%$. There were 4 kinds of replacement rate, namely $0 \%, 30 \%$, $70 \%$ and $100 \%$. The strength grade of concrete was
C40. For RAC with different replacement rates, the composition of cement and sand was kept unchanged, and the mass composition ratio of natural coarse aggregate and recycled coarse aggregate was changed under the premise that the total mass of coarse aggregate was equal.

In the test, constant vertical load was firstly applied on the top of the column through $1500 \mathrm{kN}$ hydraulic jack. According to the provisions of "JGJ 101-1996 Code for Seismic Test Methods of Buildings", the joint control method of force and displacement was adopted to load horizontally. Before yielding, load control was used to load the specimens in stages. The increment of each grade of load was $5 \mathrm{kN}$ until the steel tube at the bottom of the column reached the yield strain.

Before the specimen was yielded, the load was controlled and graded, and the load increment of each stage was $5 \mathrm{kN}$ until the steel pipe at the bottom of the column reached the yield strain, then the test piece was yielded, and the load cycle of each stage was 1 time; after the specimen was yielded, the multiple of yield displacement $\Delta y$ was taken as the grade difference to control loading. In order to facilitate the comparative analysis of test data under cyclic displacement of the same grade, the yield displacement of all specimens was uniformly set as $10 \mathrm{~mm}$ by referring to the yield displacement of the first loading specimen. Each stage of the displacement cycle was 3 times, and the loading was stopped until the load dropped below $85 \%$ of the peak load. The loading system of horizontal load was shown in figure 3.

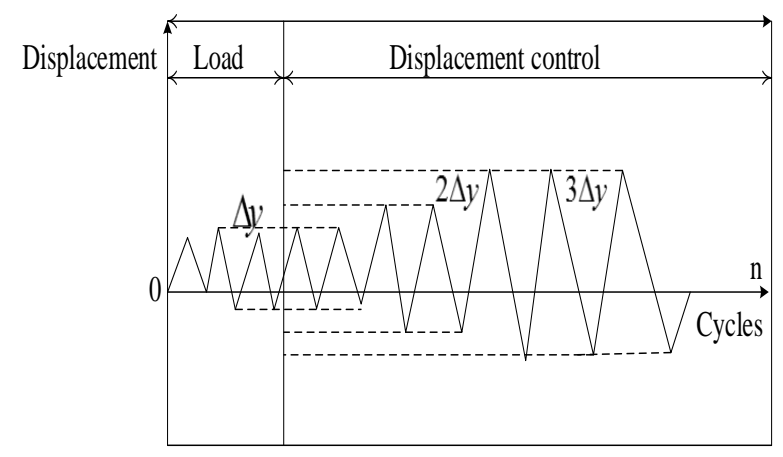

Figure 1: Loading system of horizontal load

The test measuring device mainly included displacement measuring device and strain collecting system. The horizontal displacement of the column top was measured by the displacement sensor configured by the push-pull electro-hydraulic servo actuator.

\subsection{Test results}

Low-cycle repeated loading tests were carried out on six square steel tube recycled concrete 
column specimens, and the overall failure characteristics were observed as follows: the failure process and the failure form of the specimen were similar to that of the ordinary concrete filled steel tube column, which was mainly manifested as the failure of the steel tube at the root of the specimen, and the obvious bulging waveform was formed on the side of the specimen. After the test, the external steel pipe was cut manually to observe the failure pattern of the core RAC. No transverse cracks were found along the height of the column.

The failure pattern of RAC was mainly shown as the crushed RAC bottom, and the failure range was mainly within $20 \mathrm{~cm}$ from the root of the specimen. The square steel tubes of the specimens were welded by straight welding seams. During the whole loading process, there was no cracking of the weld. The average height of the plastic hinge region of the replacement rate single parameter change specimens S-1 to S- 4 was 4.5 to $5.9 \mathrm{~cm}$, and the average height of the center of the range in which the paint was peeled off was 8.3 to $11.7 \mathrm{~cm}$; the average height of the plastic hinge region of the axial pressure ratio single parameter change specimen $\mathrm{S}-4$ to S-6 was 4.8 to $5.9 \mathrm{~cm}$, and the average height of the center of the range in which the paint was peeled off was 8.8 to $11.7 \mathrm{~cm}$.

The plastic hinge area at the bottom of all steel tubes run through the whole steel tube cross section. In general, the average height of the center of the range in which the paint was peeled off was about 2 times of the average height of the plastic hinge area.

During unloading and reverse loading, the bending wave was gradually leveled, and the bending wave in pressure side was more and more obvious. At the end of loading, the steel tube didn't bulge much at the corner, and the steel tube was bulging outwards on all sides. The bottom of the steel tube formed a relatively obvious bending plastic hinge, and the plastic hinge area covered the entire steel tube section. On the side of the specimen perpendicular to the direction of push and pull, the bulging degree of steel tube was obviously greater than that of the side of the specimen parallel to the direction of push and pull. Before the specimen was destroyed, the bonding performance between steel tube and core RAC was good. After the specimen was damaged, the metal hammer struck the surface of the steel tube, and it was found that there was a serious debonding phenomenon from the bottom of the steel tube, and the height of the debonding area was 13 $64 \mathrm{~cm}$ from the root of the specimen.

\subsection{Test analysis}

When the frame structure was affected by earthquake, some components would enter the stage of elastoplastic work. In order to maintain the bearing capacity of the frame, it was required that the beam, column and other components of the frame should have certain deformation capacity, collapse resistance, and sufficient ductility. At the same time, the basic requirement is that the column should not be destroyed before the beam. This is because the damage to the beam is local and will not pose a threat to the overall structure. Once the column is damaged, it may lead to the collapse of the entire structure, with very serious consequences. The theory of "strong column and weak beam" is based on the above concept. At the end of the test, the top of all specimens didn't bulge, and the value of the strain gauge pasted on the top of the column didn't reach the yield strain. And the bottom of the column buckled, forming a more obvious bending plastic hinge. In addition, from the perspective of the whole failure process and morphology of the specimen, it was obvious that the beam was destroyed first, and then the column foot was bulging. In conclusion, the structure met the seismic design requirements of "strong column and weak beam".

The key to ensure good ductility of structural components is to prevent premature shear failure of structural components. The structural members have certain premonition before failure, such as cracking, down warping and other phenomena. According to the premonitions, corresponding preventive measures can be taken. Therefore, structural components are required to be designed as the type of "strong shear and weak bending". In this test, the beam of the specimen first produced obvious bending cracks, and then the bending cracks were gradually transformed into oblique cracks and eventually developed into critical oblique cracks.

The failure mode was a flexural and shear failure dominated by shear failure, and the failure mode of the specimen can meet the seismic design requirements of "strong shear and weak bending".

Node is the key part of beam-column connection. Once the node is damaged, not only the beam and column connected to the node can't work normally, but also all the beams and columns above the node can't work normally. The safety and reliability of the joint area is the precondition to ensure the effective transmission of the internal forces of beams and columns. Therefore, in the design of structural components, the seismic design requirements of "strong joint and weak component" should be ensured. In this test, until the end of loading, the joints of the specimen were not damaged, meeting the seismic design requirements of "strong node and weak component".

For the recycled concrete hollow block masonry filled wall- square steel tube recycled concrete frame structure, from the perspective of the failure process and morphology of the specimen, the failure of the specimen started from the filled wall. The filled wall acted as the first seismic defense line and the square 
steel tube recycled concrete frame acted as the second seismic defense line. From the perspective of the whole test process, recycled concrete hollow block masonry filled wall - square steel tube recycled concrete frame structure met the seismic design requirements of "multiple seismic defense lines".

\subsection{Test conclusions}

After the low-cycle repeated loading test of square steel tube RAC column - steel bar RAC deep flexural beam frame, the failure process and failure form of the specimen were observed, and the main conclusions were drawn as follows: firstly, the failure process and morphology of the RAC frame structure of square steel tube were similar to that of the ordinary square steel tube concrete frame structure.

The stress process can be divided into three stages: elastic work, elastoplastic work and rapid failure. Secondly, the node plate at the end of the beam can ensure the bonding effect between the rebar RAC beam and the square steel tube RAC column at the interface of the two, and can effectively transfer the shear force at the end of the beam to the square steel tube RAC column, so as to improve the stiffness and strength at the beam-end, so that the beam was not damaged at the end with the maximum stress. Thirdly, according to the relevant design in this study, the seismic design requirements of "strong column and weak beam, strong shear and weak bending, strong node and weak component" can be met. At the same time, the recycled concrete hollow block masonry filled wall can be used as the first seismic defense line of square steel tube recycled concrete frame structure. Fourthly, and there was no obvious bending plastic hinge in the deep flexural beam of rebar RAC beam, so special attention should be paid to prevent its sudden shear failure under strong earthquake.

\section{Conclusion Analysis of Seismic Performance Test of Square Steel Tube Recycled Concrete Frame}

\subsection{Load-vertex displacement hysteretic curve}

Hysteretic curve reflects the relation curve between the force and displacement of the specimen under the action of repeated low-cycle load. It can be used to analyze the seismic bearing capacity, stiffness, ductility, energy dissipation performance and other indicators of the specimen. It is not only the comprehensive embodiment of seismic performance of structure or component, but also the important basis of analyzing the elastoplastic dynamic response characteristics of structure or component.

Figure 2 is the measured load-vertex displacement hysteretic curve of each specimen, where the load is measured by the load sensor attached to the MTS servo actuator and the displacement is measured by the external precision displacement sensor.

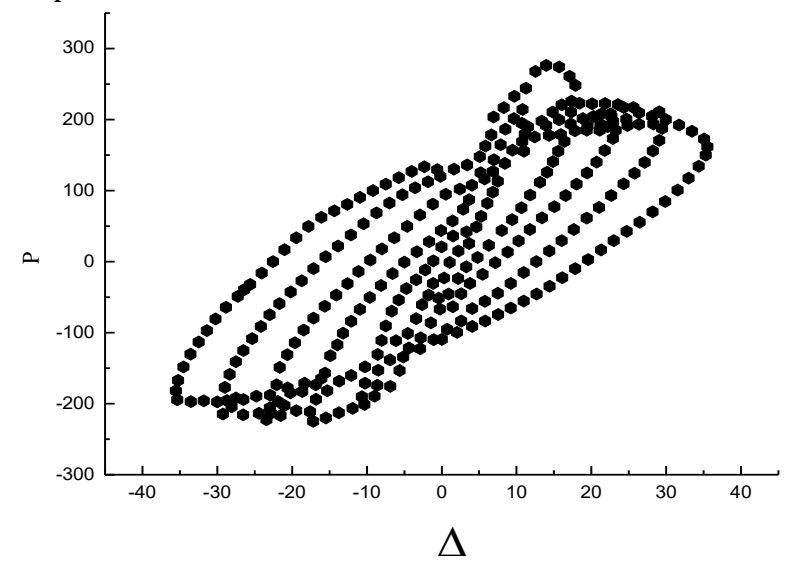

Figure 2: The measured hysteretic curve of the specimen

It can be concluded from the figure that the hysteretic curve of square steel tube recycled concrete column - recycled concrete deep flexural beam frame has the following characteristics: in the force control stage, the load-displacement relation curve of the specimen basically presented a linear change, the surrounding area was very small, and its stiffness didn't change significantly. Until the end of the force control, the specimen didn't produce obvious residual deformation, and the structure was in the elastic working stage. At the initial stage of controlled loading, the hysteresis ring of the specimen started to open, and when the positive and negative loads were reduced to zero, the specimen showed some residual deformation, and then the beam end of the specimen started to show oblique cracks. When the load reached $\pm 2 \mathrm{~d}$, the structure began to yield, and when the positive and negative loads were reduced to zero, the specimen showed obvious residual deformation, and the structure began to enter the stage of elastic-plastic work. In this stage, with the increase of the number of cycles, the hysteresis loop of the specimen was deviated to a certain extent, but it was not obvious, and there was no obvious degradation in the strength and stiffness of the structure. After yielding, the bearing capacity of the structure continued to increase. When the load reached the peak point, the bearing capacity of the specimen would show a significant decline process, indicating that the RAC beam would be shear failure and quit the work. With the increase of the number of cycles, the strength and stiffness of the specimen were degenerated significantly. When the positive and negative loads were discharged to 
zero, the specimen would have large residual deformation and the structure would have obvious cumulative damage. The hysteretic loop of the specimen was also fuller and showed better energy dissipation performance. With the further increase of the horizontal displacement, the bearing capacity of the specimen gradually was decreased to about $85 \%$ of the peak load. At this stage, the hysteresis loop of the specimen presented a full spindle shape. With the increase of the number of cycles, the hysteresis loop was deviated significantly, the stiffness and strength of the specimen was degenerated obviously, and the cumulative damage of the specimen was further increased. With the increase of displacement, the hysteretic loop of the specimen gradually deviated from the displacement axis and became plump. In the whole process of loading, the hysteretic curve of all specimens did not shrink, but presents a full fusiform, which showed that the structure had good energy dissipation performance.

\subsection{Skeleton curve}

Skeleton curve refers to the connection of the first cycle peak points of each grade of load in the hysteretic curve, which can reflect the bearing capacity, stiffness, displacement ductility and other seismic performance of the structure [15].

Figure 3 shows the measured skeleton curves of all specimens. From the figure, it can be concluded that the skeleton curve of square steel tube recycled concrete column - recycled concrete deep flexural beam frame has the following characteristics: the skeleton curves of all specimens were relatively complete, and there were rising stage, peak stage and falling stage, indicating that the specimens had gone through the elastic working stage, the elasticplastic working stage and the failure stage. For the specimens with single parameter change of replacement rate, the skeleton curve shapes of each specimen were relatively similar and almost coincided in the elastic stage. The positive and negative average peak loads of the specimens were also basically close, indicating that the replacement rate had little influence on the initial stiffness and peak bearing capacity of the structure.

When the peak load was reached, there were some differences in the falling stage of the curve. The falling range of the specimen with $100 \%$ replacement rate was slightly greater than that of the specimen with 50\% replacement rate. The falling ranges of the two were basically coincident, but the falling range of the two was significantly greater than that of the specimen with $0 \%$ replacement rate. This was mainly because the recycled aggregate had some original damage in the process of original use and crushing, which led to some tiny cracks in the interior. In addition, due to some cement mortar attached to its surface, its strength was less than that of ordinary natural aggregate. When the regenerated concrete specimen was subjected to shear failure under multi-axial stress, the failure surface of the specimen would appear at the interface or be split along the aggregate. However, for ordinary concrete specimens, the aggregate at the failure surface presented crushing failure. The failure of the specimen mainly started from the shear failure of rebar RAC deep flexural beam.

However, for specimens with different replacement rates $(50 \%, 100 \%)$, there was a certain volatility in the failure process, which led to a slightly larger reduction range of $100 \%$ replacement rate specimens than that of $50 \%$ replacement rate specimens.

The reduction stages of the two were almost identical, but the reduction range of the two was significantly greater than that of the specimens with a replacement rate of $0 \%$.

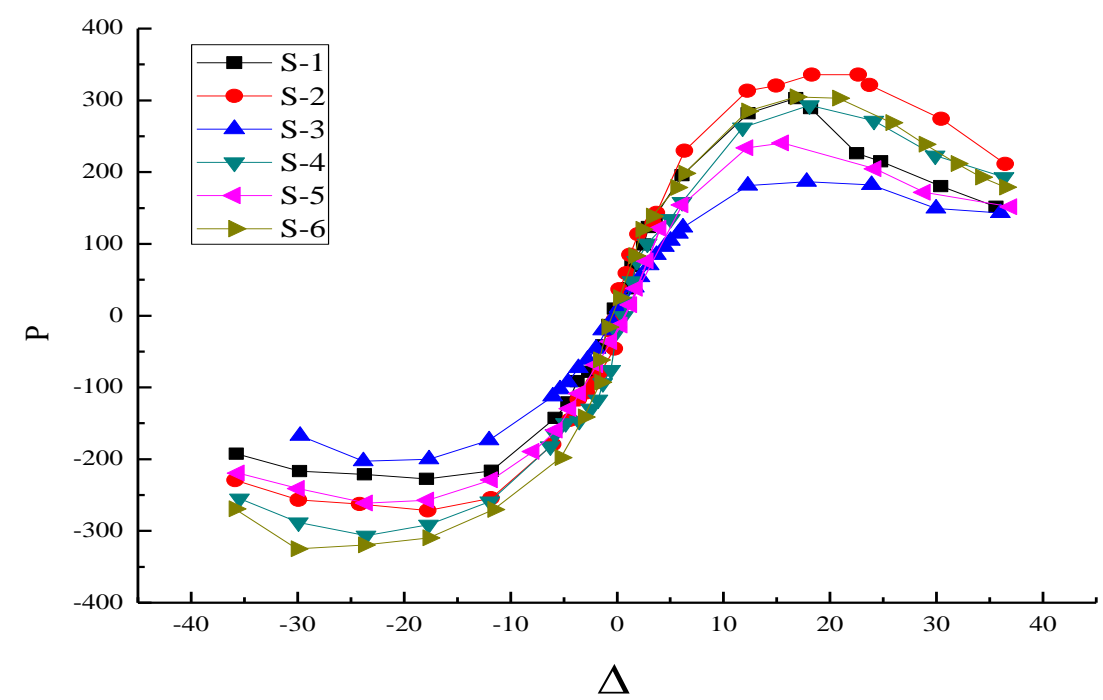

Figure 3: Measured skeleton curves of all specimens 


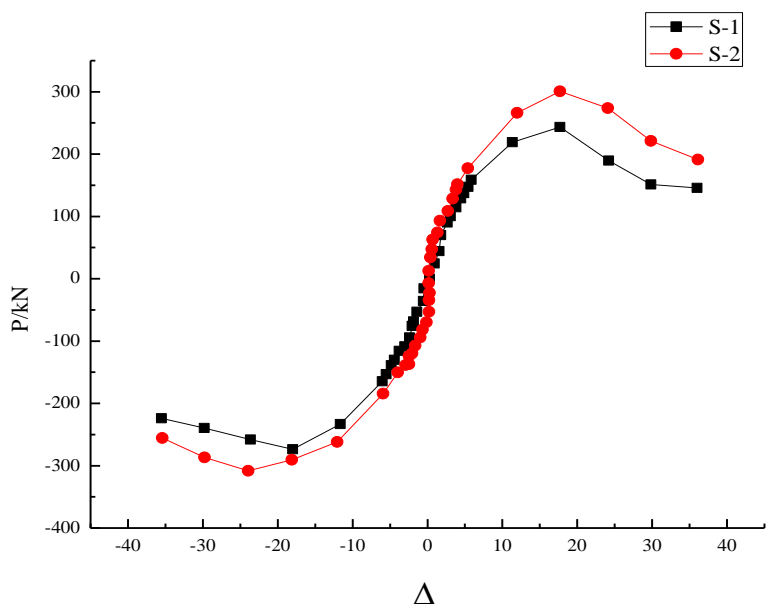

Figure 4: Impact on the skeleton curve with or without walls

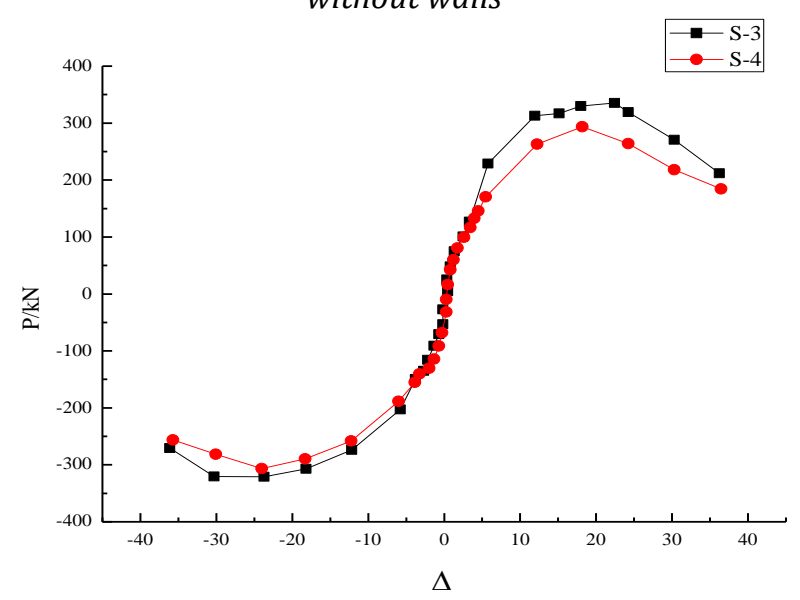

Figure 5: The influence of the stiffness of beamcolumn line on the skeleton curve

When the strength grade of concrete was improved, the initial stiffness, yield load and peak load of the specimen were all improved, but the extent of improvement was not obvious, and the decline rate of the curve was basically the same, which was mainly because the square steel tube limited the deformation of RAC, so that the influence of RAC strength was gradually reduced.

In general, RAC strength had a certain effect on the skeleton curve of the structure, but the effect was small. The linear stiffness of the beam and column had a great influence on the skeleton curve of the structure. The initial stiffness, the average yield load and peak load in positive and negative directions of S-1 were significantly increased, while the initial stiffness, positive and negative yield load and peak load of S-2 were significantly decreased. Compared with the initial stiffness of S-3, there was not much difference or even a downward trend. The positive and negative mean yield load and peak load were both increased, but the increase was not as large as that of the empty frame. Thus, it can be concluded that the linear stiffness of the beam and column had an obvious influence on the skeleton curve of the structure.
In the empty frame, the initial stiffness, yield load and peak load of the specimen can be significantly improved by increasing the linear stiffness of the beam or the column. In the frame structure with filled walls, the effect of stiffness of beam and column on the skeleton curve was smaller than that of the empty frame structure.

In addition, the differences between the reverse skeleton curves of S-4 and S-5, S-5 and S- 6 were not very large, which may be related to the force transfer process of the test piece during loading.

In the forward push process, the force between the two columns of the frame was passed through the entire RAC beam. And in the process of reverse tension, the force between the two columns of the frame was mainly transmitted through the longitudinal bar and tie rod of the RAC beam, thus the above phenomenon occurred. It can be concluded that the filled wall had a significant influence on the skeleton curve of the frame. The initial stiffness, positive and negative yield load and peak load of square steel tube recycled concrete column - rebar RAC deep flexural beam frame with filled wall were significantly greater than those without filled wall. The displacement corresponding to the peak load increased, the decrease range was also moderate, and the ductility was improved.

This was mainly because the damage of square steel tube recycled concrete column- rebar RAC deep flexural beam frame was shear fracture caused by deep flexural beam, which was brittle failure. Due to the existence of the filled wall, it played a role of restraint and strengthening for the deep flexural beam, and the filled wall itself consumed a large part of energy, thus slowing down the possibility of sudden brittle failure.

Therefore, it can be concluded that the filled wall had great influence on the skeleton curve of the square steel tube recycled concrete column- rebar RAC deep flexural beam frame.

\subsection{Residual deformation}

Residual deformation refers to the unrecoverable deformation of a structure or component after an earthquake. It not only reflects the damage degree of structure or component in the earthquake, but also reflects the post-earthquake deformation recovery ability of structure or component to a certain extent, which has an important impact on the functional recovery of post-earthquake building structure or component. The residual deformation of a building structure or component can be evaluated by the average residual deformation rate, and its calculation formula is shown in equation 1 :

$$
\delta=\frac{\left|\Delta_{r}^{+}\right|+\left|\Delta_{r}^{-}\right|}{\left|\Delta_{s}^{+}\right|+\left|\Delta_{s}^{-}\right|}
$$


Among them, $\delta$ is the average residual deformation rate, $\Delta_{r}^{+}$and $\Delta_{r}^{-}$represent the residual displacements when the load in positive and negative directions of the same loading grade is unloaded to zero, $\Delta_{s}^{+}$and $\Delta_{s}^{-}$represent the maximum displacements in positive and negative directions of the same loading stage.

The residual deformation of the specimen is most affected by the loading displacement, and the $\delta$ of the specimen increases linearly with the increase of the displacement.

When the specimen was loaded at the position of $\pm \Delta$ and $\pm 2 \Delta$, the residual deformation of the specimen was relatively small, and the $s$ of each specimen had a certain volatility, so there was no obvious rule to follow.

However, with the increase of displacement, the residual deformation of each specimen showed a certain rule with the change of each parameter.

For the single parameter change specimen with substitution rate, the $\delta$ gradually increased as the substitution rate increased. With the increase of displacement, the residual deformation of the specimen increased with the increase of replacement rate.

For the single parameter change of RAC intensity, under each load stage of $\pm 3 \Delta$ and subsequent, $\delta$ gradually decreased as the strength of the RAC increased.

Therefore, with the increase of displacement, the residual deformation of the specimen decreased with the increase of RAC strength.

For the single parameter change of column line stiffness, under each loading stage, the $\delta$ of the column line became larger as the stiffness of the column line increased. For the single parameter change of the beam line stiffness, at each loading stage after $\pm 3 \Delta$, the $\delta$ appeared to become smaller as the stiffness of the beam line increased.

For the case of infilled walls, under each loading stage, the $\delta$ appeared to be gradually smaller as the stiffness of the beam line increased. It indicated that with the increase of displacement, the residual deformation of the specimen decreased with the increase of beam line stiffness and increased with the increase of column line stiffness.

For single parameter changes with or without infilled walls, under each of the loading stages of $\pm 3 \Delta$ and subsequent, the $\delta$ of specimens with the infilled walls were smaller than the specimens without the infilled walls.

As the displacement increased, the presence of the infilled wall can reduce the residual deformation of the specimen.

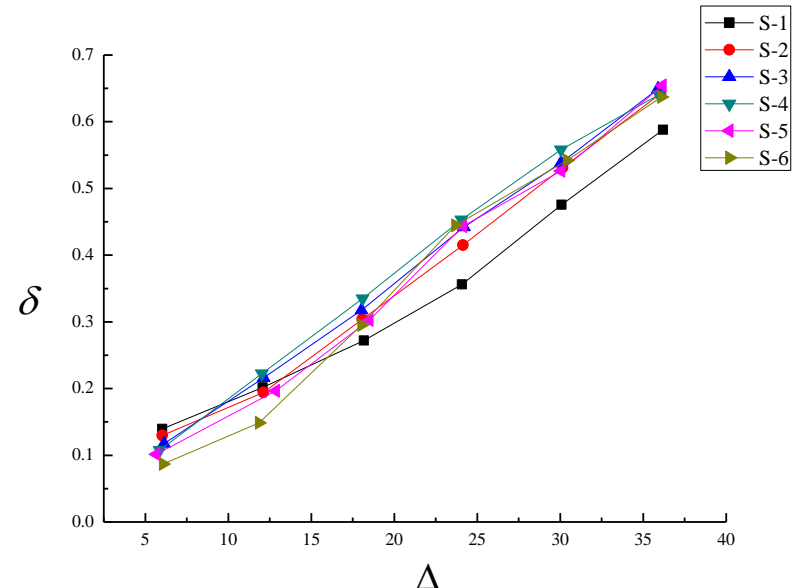

Figure 6: The average residual deformation rate of each specimen

\section{Theoretical Analysis of Seismic Performance of Square Steel Tube Recycled Concrete Frame}

On the basis of seismic test, the plane section assumption of beam and column, height of point of inflection, $P_{-} \triangle$ second-order effect of frame were analyzed. In addition, the bending strength and stiffness were calculated to expand the research content of the square steel tube recycled concrete frame, so as to provide relevant basis and reference for further theoretical research and engineering application.

\subsection{Assumption analysis of plane section}

The assumption of plane section is the theoretical basis for the design and calculation of structural members. For general reinforced concrete members and prestressed concrete members, they can meet the requirements of the assumption of plane section.

For shear deformed members, such as deep beams with a span to height ratio less than 2 , the flat section assumption is no longer applicable. The plane section assumption of structural components is mostly studied at the component level under static load, while the research based on the structure level is relatively rare. Under the action of low-cycle repeated load, the plane section assumption of square steel tube recycled concrete column and rebar RAC deep flexural beam is verified based on the structure level, which provides a basis for further theoretical research.

Figure 5 shows the strain change of the column bottom section along the direction of section height during the loading process. Among them, the section height of No. 20 measuring point was recorded as 0 , the section height of No. 24 measuring point represented column width, and the section height of No. 21-23 measuring point was interpolated on average. 


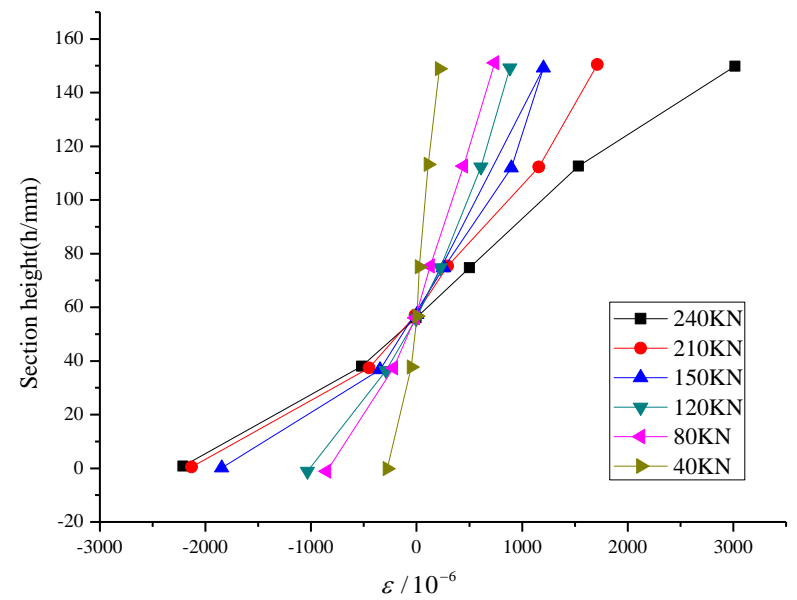

Figure 7: The strain distribution along the height of the column bottom section

It can be concluded from the figure that the strain of the section was basically conformed to the assumption of the plane section within a certain plastic rotation range before and after the strain of the square steel tube reaches the yield strain. It was shown that the section strain of the square steel tube recycled concrete column was consistent with the assumption of flat section even under the action of low frequency cyclic loading based on the structural level.

Figure 6 showed the strain change of beam end section along the direction of section height during loading. Among them, the section height of No. 101 was recorded as 0 , the section height of No. 105 was beam height, and the section height of No. 102 104 was interpolated on average.

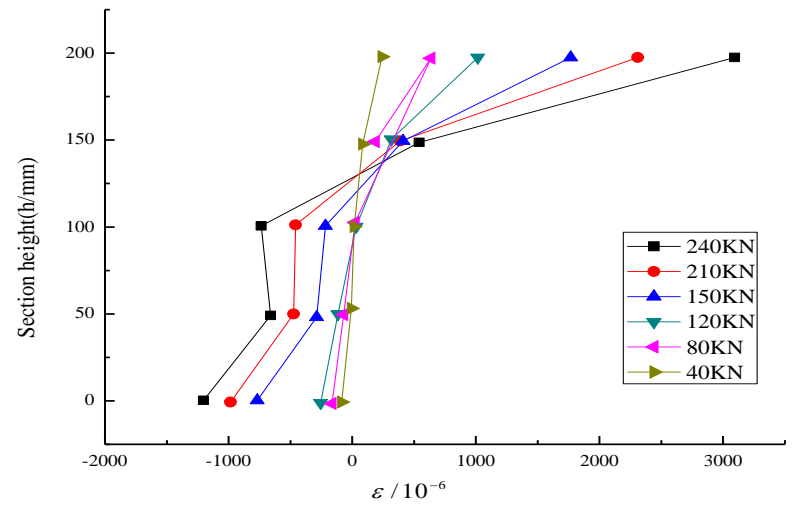

Figure 8: Strain distribution of beam end section along height direction

It can be concluded from the figure that at the early stage of loading, the cross-section strain of the beam was basically conformed to the assumption of the plane section. However, with the increase of load, the influence of shear stress was increased gradually, and the strain of section was no longer conformed to the assumption of plane section. It showed that in the early stage of loading, the section strain of rebar RAC deep flexural beam was basically conformed to the assumption of plane section, but with the continuous increase of load, its section strain was no longer conformed to the assumption of plane section.

\subsection{Rigidity computation}

The specimen can be calculated with the wall frame parallel model.

$$
K_{f w}=K_{f}+K_{e w}
$$

Among them, $K_{f}$ and $K_{e w}$ is the lateral stiffness of the frame and the filled wall in the initial stage.
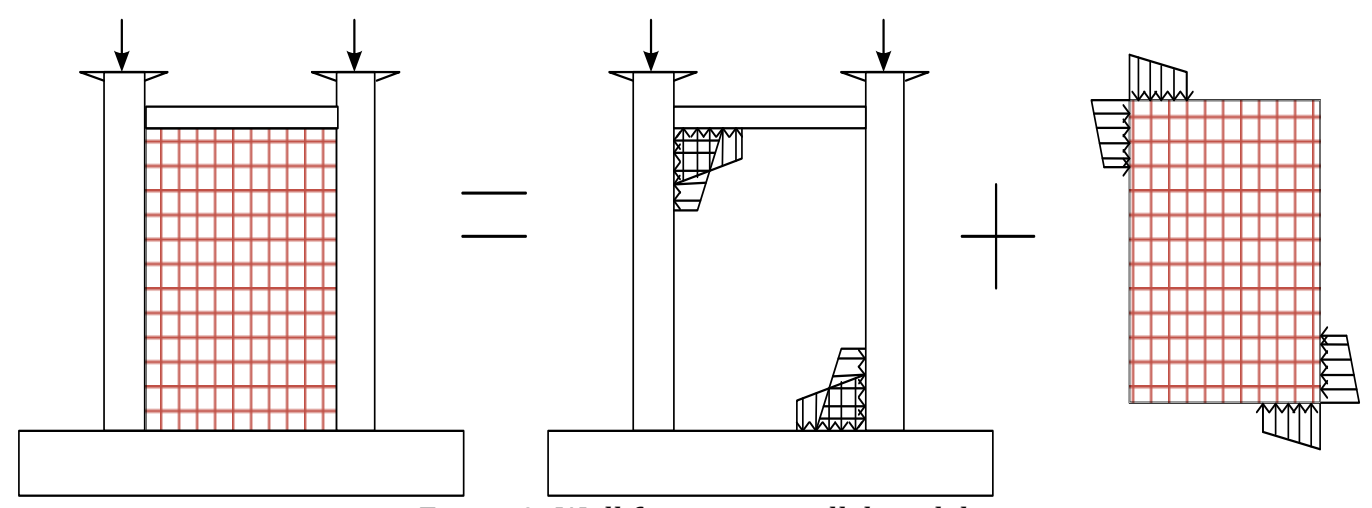

Figure 9: Wall frame in parallel model

During the test, the measured value of the initial stiffness of the specimen was the ratio of the sum of the absolute values of the positive and negative loads of the first level and the sum of the corresponding absolute values of the deformation. At this time, the displacement value of the specimen was relatively small. When the filled wall was added, the displacement value of the specimen became smaller, which had a greater impact on the measured value of its initial stiffness, thus making the test value more discrete. The measured results of the test also confirmed this phenomenon.

The measured stiffness value of the filled wall with obvious cracks was taken as its test value, and the calculated value was calculated according to equation 3: 


$$
K_{f w}=K_{f}+\alpha K_{e w}
$$

$K_{f}$ represents the initial elastic stiffness of the frame; $\alpha$ represents the participation coefficient of the filled wall, and its value was $0.2 ; K_{e w}$ is the initial lateral stiffness of the filled wall when it is not cracked, and its calculation formula is:

$$
K_{e w}=\frac{1}{\frac{H_{w}^{3}}{3 E_{w} I_{w}}+\frac{u H_{w}}{G_{w} A_{w}}}
$$

Among them, $H_{w}$ represents the wall height; $E_{w}$ represents the elastic modulus of the filled wall; $I_{w}$ represents the inertia moment of the cross section of the filled wall; $u$ is the non-uniformity coefficient of shear stress, which can be taken as 1.2 for the rectangular section; $G_{w}$ represents the shear modulus of the filled wall, $G_{w}=0.4 E_{w} ; A_{w}$ represents the cross-sectional area of the filled wall.

After calculation, the test value was in good agreement with the calculated value.

Thus, it can be concluded that the lateral stiffness of the recycled concrete hollow block masonry filled wall - square steel tube RAC frame can be calculated according to this method.

\subsection{Strength calculation}

The interlaminar shear capacity of square steel pipe RAC frame without infill wall is mainly composed of the shear strength of each column. When the failure forms and ductility of each column are similar, the shear strength between layers can be considered as the sum of the shear strength of each column, that is:

$$
Q_{y}=\sum Q_{y i}
$$

Among them, $Q_{y}$ represents the shear strength of a certain layer of frame, $Q_{y i}$ represents the shear strength of column i of this frame layer.

Therefore, in order to find the shear strength between layers of the frame, it is necessary to find the shear strength of each column.

In this study, the modified inverse bending point method was mainly used to calculate the shear strength of the frame column under the bending load, the shear bearing capacity between the layers of the frame was obtained, and the calculated value was compared with the measured value in the test, so as to discuss the calculation method of the interlayer shear strength of the square steel tube RAC column - rebar RAC deep flexural beam framework.
The modified inverse bending point method is to adjust the height of the inverse bending point of the frame structure based on the inverse bending point method. In accordance with the relevant provisions of the modified inverse bending point method, the height of the inverse bending point of the specimen is taken as $y=0.55 \mathrm{~h}$ in study.

The calculation model is shown in Figure 10.

And the shear force of the frame column can be easily calculated by the following formula:

$$
V=M_{B A} / y
$$

When the modified inverse bending point method was used for calculation, the interlayer shear bearing capacity of the frame column can be calculated as follows:

$$
Q_{y i}=M_{B A}^{y} / \mathrm{y}
$$

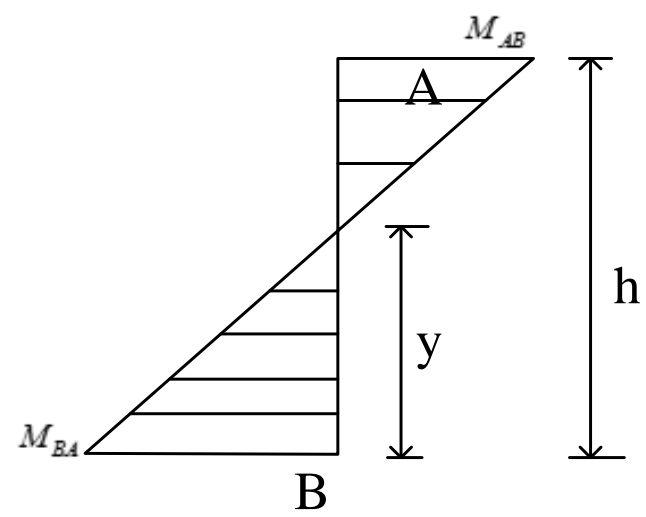

Figure 10: Calculation model

Among them, $M_{B A}^{y}$ represents the flexural capacity of the section under the bending load of the column. Different procedures have different methods of calculation

For the interlaminar shear strength of the square steel tube RAC frame with filled wall, the wall frame parallel model was used for calculation:

$$
Q_{f w}^{c}=Q_{f}^{c}+Q_{w}^{c}
$$

Among them, $Q_{f}^{c}$ represents the interlayer shear strength of an empty frame without filler wall, which can be calculated according to the analysis in the above section;

$Q_{w}^{c}$ represents the shear strength of the filled wall. In this test, the following formula can be used for simple calculation:

$$
Q_{w}^{c}=A_{w} \times f_{v}
$$

Among them, $A_{w}$ represents the anti-shearing section area of the filled wall, and $f_{v}$ represents the design value of shear strength of filled wall. 
Table 2. The comparison between the calculated value and the experimental value

\begin{tabular}{|c|c|c|c|c|}
\hline Specimen & $\begin{array}{c}\text { Experimental } \\
\text { value } Q_{f w}^{t}\end{array}$ & $\begin{array}{c}\text { Calculated } \\
Q_{f w}^{c}\end{array}$ & $Q_{f w}^{t} / Q_{f w}^{c}$ & $\begin{array}{c}K_{f w}^{t} / \mathrm{K}_{f w}^{c} \text { aver } \\
\text { age value }\end{array}$ \\
\hline $\mathrm{S}-1$ & 303.8 & 281.2 & 1.07 & \multirow{2}{*}{1.075} \\
\hline $\mathrm{S}-2$ & 332.4 & 310.3 & 1.07 & \\
\hline
\end{tabular}

Table 2 compares the calculated value and measured value calculated by this method. The unit of $Q_{f w}^{c}$ and $Q_{f w}^{t}$ were both kN. It can be concluded from the table that the test value was in good agreement with the calculated value. Therefore, it can be concluded that the interlayer shear bearing capacity of the concrete hollow block masonry filled wall - square steel tube RAC frame can be calculated and analyzed with reference to this method.

Firstly, the plane section assumption of beam and column section was analyzed with strain data obtained. Then, the correlation analysis of the $P-\Delta$ second-order effect was carried out.

At the same time, the strength and stiffness of the RAC frame were analyzed with the relevant calculation model according to the domestic and foreign codes. At the early stage of loading, the section strain of the rebar RAC deep flexural beam conformed to the assumption of plane section. However, with the increase of load, the section strain was no longer conformed to the assumption of plane section, while the section strain of square steel tube RAC column was conformed to the assumption of plane section.

Before yield load, the second-order effect of P-d had little influence on the horizontal bearing capacity and stiffness of the frame.

When the peak point was reached, the influence of the $P-\Delta$ second-order effect gradually became larger, and the influence of the $P-\Delta$ second-order effect on the horizontal bearing capacity and stiffness of the frame structure was much weaker than its influence on the component.

\section{Conclusion}

By means of experimental research and theoretical analysis, the related seismic performance of square steel tube recycled concrete column recycled concrete deep flexural beam combination frame was studied.

And relevant conclusions can be drawn as follows: firstly, the failure process and morphological stress process of square steel tube recycled concrete column - recycled concrete deep flexural beam frame can be divided into three stages: elastic work stage, elastoplastic work stage and rapid failure stage.

Secondly, the node plate at the end of the beam can ensure the bonding effect of the beam and column at the interface joint and can effectively transfer the shear force at the end of the beam to the RAC column of the square steel tube, so as to improve the stiffness and strength of the beam-end. At the same time, according to the relevant design in this study, the seismic design requirements of "strong column and weak beam, strong shear and weak bending, strong node and weak component" can be met.

Thirdly, the recycled concrete hollow block masonry filled wall can be used as the first seismic defense line of square steel tube recycled concrete frame structure and can significantly improve the seismic bearing capacity of square steel tube recycled concrete frame.

Fourthly, the skeleton curves of the specimens all had complete rising, peak and descending stages.

The replacement rate of coarse aggregate had little effect on the rising and peak stages of the skeleton curve, but it had some effect on the falling stage. RAC strength had a certain effect on the skeleton curve of the specimen, but the effect was relatively small.

The change of stiffness of beam line and column line, and the presence or absence of filled wall had obvious influence on the skeleton curve of the frame.

The square steel tube RAC structure had the advantages of simple construction and good seismic performance, it can effectively solve the problem of construction waste, so it has wide application value.

In order to accelerate the research work and engineering popularization of square steel tube RAC structure, the following problems need to be further solved: first, the source of coarse aggregate and related advanced equipment research and development problems.

The research on the crushing equipment and related process method of recycled aggregate in China is still relatively backward, so it is of great significance to develop the advanced process equipment needed for the production of recycled aggregate.

Second, the mechanical properties under longterm load.

The recycled aggregate has a high mud content, and due to the cement mortar and micro-cracks on its surface, under long-term load, the shrinkage and creep of the RAC made by it is greater than that of ordinary concrete. In engineering applications, the structure is generally under long-term load under the action of self-weight. 
Therefore, it is of great significance to study the related mechanical properties of RAC structure under long-term load.

\section{Acknowledgement}

Research startup subject of Yangtze Normal University: 2017KYQD16.

\section{References}

[1] Behnam, B., Ronagh, H. R., \& Lim, P. J. (2016). Numerical evaluation of the post-earthquake fire resistance of cfrp-strengthened reinforced concrete joints based on experimental observations. European Journal of Environmental and Civil Engineering, 20(2), 142-160.

[2] Behnam, B., Lim, P. J., \& Ronagh, H. R. (2015). Plastic hinge relocation in reinforced concrete frames as a method of improving postearthquake fire resistance. Structures, 2, 21-31.

[3] (2015). Modelling and simulation of earthquake resistant $3 \mathrm{~d}$ woven textile structural concrete composites. Composites Part B: Engineering, 81, 91-97.

[4] Jure Žižmond, \& Matjaž Dolšek. (2016). Evaluation of factors influencing the earthquakeresistant design of reinforced concrete frames according to eurocode 8. Structure and Infrastructure Engineering, 12(10), 19.

[5] Zulkarnain, F. (2018). Development of k-300 concrete mix for earthquake-resistant housing infrastructure in indonesia. International Journal of Advanced Research, 5(9), 328-335.

[6] Yiqiu, L. U., \& Liang, H. (2015). Quantitative research of ductility and drift in chinese code for reinforced concrete earthquake- resistant walls. Earthquake Engineering \& Engineering Dynamics.
[7] Shefer, Y. V., Ordobaev, B. S., Romanenko, S. V., \& Antonevich, O. A. (2015). Conception of low-rise earthquake-resistant energy-efficient buildings. IOP Conference Series: Materials Science and Engineering, 81, 012086.

[8] Wang, M., Zhao, X., Ji, X., \& Zhao, Z. (2015). Earthquake resistant behavior on seismic strengthening of typical rural brick-wood structure in beijing. Journal of Civil Architectural \& Environmental Engineering (6), 62-69.

[9] Louzai, A., \& Abed, A. (2015). Evaluation of the seismic behavior factor of reinforced concrete frame structures based on comparative analysis between non-linear static pushover and incremental dynamic analyses. Bulletin of Earthquake Engineering, 13(6), 1773-1793.

[10] Fardis, M. N. (2015). Seismic design of concrete buildings to eurocode 8 . Crc Press.

[11] Eid, R., \& Paultre, P. (2017). Compressive behavior of frp-confined reinforced concrete columns. Engineering Structures, 132, 518-530.

[12] Oinam, R. M., \& Sahoo, D. R. (2016). Seismic rehabilitation of damaged reinforced concrete frames using combined metallic yielding passive devices. Structure and Infrastructure Engineering, 1-15.

[13] Yaoting, Z., Li, Y., \& Jiang, Z. (2017). Research on the design method of strong column and weak girder of prestressed concrete frame. Journal of Hunan University, 44(1), 65-76.

[14] Bechtoula, H., Kono, S., Watanabe, F., Mehani, Y., Kibboua, A., \& Naili, M. (2015). Performance of hsc columns under severe cyclic loading. Bulletin of Earthquake Engineering, 13(2), 503538.

[15] Bestuzheva, A. S. (2015). Characteristics of the spatial behavior of a dam with a bituminousconcrete diaphragm during earthquakes. Power Technology \& Engineering, 48(5), 331-342. 